Paidéia, 2006, 16(33), 43-50

\title{
EXPRESSÃO DA CAPACIDADE DE EMPATIA EM BEBÊSS DE 8 E 18 SEMANAS ${ }^{1}$
}

\author{
Kornilia Hatzinikolaou ${ }^{2}$ \\ Centro Universitário Luterano de Manaus
}

Resumo: Este estudo investigou o padrão temporal e expressivo da capacidade de empatia em bebês de 8 e 18 semanas no contexto de interações face-face entre 90 duplas de mãe-bebê. As interações foram analisadas em tempo real e através de micro-análise. Alguns comportamentos infantis apresentaram maior probabilidade de fazerem parte do padrão expressivo da empatia do que outros. Ainda, o padrão expressivo se manifestou diferente em instâncias de empatia com emoções negativas e instâncias de empatia com emoções positivas comunicadas pela mãe. Em relação ao padrão temporal, observou-se que a manifestação da capacidade de empatia ocorreu dentro de um intervalo de tempo igual de $1 / 2$ segundo antes e 1 segundo depois da mudança emocional da mãe. Os resultados indicam a necessidade de reavaliação das proposições tradicionais sobre as capacidades comunicativas precoces de bebês, e sugerem uma coerência entre os achados e as proposições teóricas contemporâneas na área da Psicologia Infantil.

Palavras-chave: empatia; interação mãe-bebê; intersubjetividade.

\section{THE EXPRESSION OF EMPATHY IN INFANTS OF 8 AND 18 WEEKS}

Abstract: The present study examined the expressive and temporal pattern of empathy in 8- and 18week-old babies. Infant empathy was observed in the context of face-to-face interactions of 90 mother-infant dyads, seen both at 8 and 18 weeks. These interactions were observed and analyzed both, in real time and micro-analytically. Certain infant behaviors were more likely to be involved in the expressive pattern of infant empathy than others. In addition, the expressive pattern of infant empathy was found to be quite different in the case of the infant empathizing with positive and negative maternal emotions. In relation to its temporal pattern, it was observed that infant empathy occurred in a time-interval of $1 / 2$ second before and 1 second after the emotional change in the mother. The results suggest the re-evaluation of traditional beliefs concerning early infant communicative capacities, while contemporary theoretical contexts are discussed.

Key words: empathy; mother-infant interaction; intersubjetivity.

Introdução: A Teoria da Intersubjetividade Inata (Trevarthen, 1979, 1998) proporcionou um olhar inovador aos primeiros meses da vida humana, sugerindo que: a) a mente humana está bem preparada e motivada para se envolver, comunicar e compartilhar com outras pessoas desde o nascimento; b) os bebês são agentes intencionais desde o seu nascimento, possuindo uma consciência ativa. O conceito de "intersubjetividade" tem sido frequentemente usado em Psicologia e Filosofia para explicar a capacidade intrínseca, ou em desenvolvimento, dos seres humanos para participar de significados com membros da

\footnotetext{
${ }^{1}$ Artigo recebido em 02/08/2005 e aceito para publicação em 13/ 06/2006.

${ }^{2}$ Endereço para correspondência: Kornilia Hatzinikolaou, Rua das Samambaias, 623, Conjunto Tiradentes, Manaus-AM, CEP: 69083-320,E-mail: corinahatzinikolaou@hotmail.com ou khatzinikolaou@ufam.edu.br
}

sua espécie. Trevarthen usou o termo "intersubjetividade" para se referir à ligação entre dois sujeitos que ativamente transmitem um para o outro o entendimento da sua experiência no mundo. A intersubjetividade inata promove a formação e favorece a manutenção do vínculo entre mãe-bebê; através desta e outras relações sociais, o bebê é sujeito na aprendizagem cultural (Trevarthen \& Aitken, 2001). Entretanto, desde os primeiros estudos sobre as capacidades comunicativas precoces de bebês, tem sido sugerido que o desenvolvimento de tais capacidades últimas é dependente de cuidados simpáticos e sensíveis, e de maternagem e paternagem responsivas (Brazelton, Koslowski \& Main, 1974).

A introdução da Teoria da Intersubjetividade Inata motivou uma série de estudos empíricos na área da Psicologia do Desenvolvimento, que visaram ob- 


\section{Kornilia Hatzinikolaou}

servar e descrever as capacidades comunicativas precoces da espécie humana. Assim, atualmente, muitos estudiosos do desenvolvimento humano não consideram mais os recém-nascidos e os bebês com menos do que um ano de vida como seres vivos governados por impulsos e reflexos, incapazes de se relacionar ativamente com seu ambiente, ou confusos em relação aos limites do Eu e Não-Eu. Ao contrário, as capacidades dos bebês de comunicar suas próprias emoções e intenções, de perceber as emoções e as intenções dos outros, e de responder apropriadamente a estas são amplamente reconhecidas por teóricos e pesquisadores da área da Psicologia Infantil (Hatzinikolaou \& Murray, 2001; Hatzinikolaou, 2002; Kugiumutzakis, 1998; Murray \& Trevarthen, 1985; Reddy, 2003; Stern, 2000).

Embora as capacidades comunicativas precoces supracitadas, investigadas nos últimos 25 anos, não incluíam sempre a capacidade de empatia - aqui definida como a capacidade de perceber diretamente (sem participação de representações mentais), e simultaneamente vivenciar, o estado emocional de uma outra pessoa quando em comunicação intersubjetiva (Hatzinikolaou, 2002), sendo que seus padrões expressivos no primeiro ano de vida não foram ainda explorados empiricamente. Alguns teóricos (Murray, 1989; Trevarthen, 1979), discutindo as qualidades da comunicação intersubjetiva entre mãe-bebê, tinham contemplado situações nas quais bebês de alguns meses participavam em interações com parceiros sensíveis de tal maneira que permitiam inferir que eles tinham a capacidade de empatia: "qualquer um dos parceiros pode iniciar uma 'demonstração’ ou ‘uma ação expressiva’ e ambos agem para manter o compartilhamento e a troca de iniciativas. Ambos os parceiros expressam impulsos propositais complexos numa forma contagiante para o outro. É difícil perceber o conteúdo da comunicação, exceto o compartilhamento e a troca por si” (Trevarthen, 1979). Porém, estudos empíricos, especificamente construídos para investigar se a capacidade de empatia está presente em bebês durante o primeiro ano de vida, são extremamente escassos.

Assim, o presente trabalho teve como objetivos: a) investigar se bebês de apenas 8 e 18 semanas apresentam a capacidade de empatia, b) descrever o padrão expressivo da capacidade de empatia em be- bês de 8 e 18 semanas, e c) examinar o padrão temporal da capacidade de empatia em bebês de 8 e 18 semanas, tendo como contexto a interação face-aface entre mãe - bebê.

\section{Método}

$\underline{\text { Participantes }}$

Mulheres primíparas foram convidadas durante seus exames de rotina na $20^{\mathrm{a}}$ semana de gravidez numa Maternidade (Royal Berkshire Maternity Hospital) da cidade de Reading na província de Berkshire, Inglaterra, para participar de um estudo sobre desenvolvimento social de bebês. Neste primeiro contato, elas preencheram o Predictive Index (Cooper, Murray, Hooper \& West, 1996) que permite a identificação de sujeitos em risco para desenvolver transtornos mentais no período pós-parto.

As mulheres foram novamente contatadas depois do parto, e as que tiveram gestação entre 37 e 42 semanas, e recém-nascidos com peso maior do que 2500 gramas foram incluídas na amostra. Finalmente, a amostra foi constituída por 90 duplas de mãebebê. Das mães que participaram do estudo, 77 tinham sido identificadas no período pré-natal em risco de desenvolver transtornos mentais após o parto, 25 das quais foram diagnosticadas com depressão no período pós-parto. A média da idade materna era de 31 anos. As 90 duplas de mãe-bebê foram observadas na $8^{\text {a }}$ e $18^{\mathrm{a}}$ semanas.

\section{Procedimento}

A filmagem da interação mãe-bebê foi feita em ambiente especialmente estruturado para receber mães com bebês pequenos. $\mathrm{O}$ bebê ficava numa 'baby sitter', em cima de uma mesa larga. A mãe sentava na frente desta mesa, e de frente para o bebê. No lado direito da cadeira do bebê, em cima da mesa, havia um espelho $(0.45 \times 0.80 \mathrm{~cm}$.), apropriadamente ajustado para refletir o rosto da mãe. Uma câmera, colocada alguns metros atrás da mãe, no lado esquerdo, conseguia focar ambos.

A interação face-a-face durava 5 minutos. A instrução dada para mãe era "brinque com seu bebê como você faz em casa”, e a seguira pesquisadora deixava o par sozinho no quarto para que ficassem mais a vontade. 


\section{Análise de dados}

As interações filmadas foram analisadas em duas maneiras: a) em tempo real para todas as 90 duplas, e b) através de micro-análise, usando o software Observer 4.0, para 21 duplas de mãe-bebê.

a) Análise em tempo real: A interação facea-face das 90 duplas, nas duas idades, observada em tempo real, visou verificar se bebês com 8 e 18 semanas têm a capacidade de empatia. Para responder a esta questão, foi criado o seguinte protocolo: os momentos que a mãe apresentava índices comportamentais (tonalidade de voz, expressão facial, conteúdo da fala, expressões corporais) apontando mudanças no seu estado emocional (de negativo para positivo, e de positivo para negativo) eram anotados. A seguir, o bebê era observado para verificar se apresentava índices comportamentais (vocalizações, expressão facial, expressões corporais) de que tinha percebido a mudança no estado emocional da mãe.

Das 90 duplas, vinte (22\%) foram excluídas da análise por vários motivos ${ }^{1}$. Assim, a capacidade de empatia foi analisada em 70 duplas (78\%), todas observadas nas duas idades. Dos bebês incluídos na análise, 84.3\% apresentaram no mínimo um episódio de empatia durante os cinco minutos de interação nas 8 semanas, e $80 \%$ nas 18 semanas. Na tabela 1 acham-se os resultados para os episódios de empatia nas 8 e 18 semanas.

Tabela 1 - Análise descritiva dos episódios de empatia nas 8 e 18 semanas

\begin{tabular}{|l|l|l|}
\hline \multirow{2}{*}{ Media (dp) } & $\begin{array}{l}\text { 8 semanas } \\
(\mathbf{N}=\mathbf{7 0})\end{array}$ & $\begin{array}{l}\text { 18 semanas } \\
(\mathbf{N}=\mathbf{7 0})\end{array}$ \\
\cline { 2 - 3 } Mediana & $5.07(3.7)$ & $4.70(3.9)$ \\
\hline P25 & 2.75 & 5 \\
\hline P75 & 7 & 1 \\
\hline
\end{tabular}

Assim, verificou-se que os bebês apresentaram uma média de mais ou menos cinco episódios de empatia na interação face-a-face com sua mãe nas 8 e 18 semanas, sendo que $75 \%$ dos bebês de 8 e 18

\footnotetext{
${ }^{1}$ (p.e, filmagem inapropriada para análise detalhada das expressões faciais, choro inconsolável do bebê).
}

semanas apresentaram entre um e sete episódios de empatia. A média se mostrou igual à mediana, o que sugere seja normal a distribuição do número de episódios de empatia para ambas as idades.

Verificação da Fidedignidade na Análise em Tempo Real: Um segundo observador codificou 12 interações (17\% da amostra incluída na análise) entre mãe-bebê, aleatoriamente escolhidas. Dois foram os procedimetnos para se examinar a fidedignidade: a) para verificar se os dois observadores identificaram o mesmo número de episódios de empatia foi utilizada a correlação intra-classe $(\mathrm{a}=.95)$, e, para verificar se os mesmos episódios de empatia foram identificados foi calculado o coeficiente $\mathrm{K}(\mathrm{k}=.774, \mathrm{p}<.01)$.

b) Micro - análise: Vinte e um dos bebês que apresentaram no mínimo quatro episódios de empatia na interação face-a-face em ambas as idades, foram incluídos na micro-análise que tinha como objetivo a investigação do padrão expressivo e temporal da capacidade de empatia. Assim, para cada uma das duplas, oito episódios de empatia foram analisados (quatro de cada uma das duas idades investigadas). Para cada episódio de empatia, 15 segundos de interação eram micro-analisados ( 5 segundos antes, e 10 segundos depois da mudança no estado emocional da mãe).

A criação do esquema de codificação a ser usado na micro-análise dos episódios de empatia envolveu as 21 duplas de mãe-bebê, que foram repetidamente observadas. Os índices comportamentais do bebê e da mãe mais frequentemente associados com a expressão da capacidade de empatia dele foram anotados. E, visando alcançar os objetivos deste estudo, somente o estado emocional do bebê e da mãe, a qualidade de atenção dele e dela, e a qualidade do olhar do bebê fizeram parte do esquema de codificação.

Verificação da Fidedignidade da Micro-Análise: Um segundo observador codificou as interações de cinco duplas, em ambas as idades (totalizando 40 episódios de empatia). O grau de concordância entre observadores em relação à manifestação de cada um dos índices comportamentais do bebê e da mãe foi avaliado com o coeficiente K. As Tabelas 2 e 3 apresentam os escores do coeficiente $\mathrm{K}$ para cada um dos índices comportamentais do bebê e da mãe avaliados. 
Tabela 2- Escores do coeficiente K para as categorias comportamentais referentes à mãe.

\begin{tabular}{|l|l|l|l|l|l|}
\hline Atenção & $\mathbf{K}$ & $\begin{array}{c}\text { Expressão } \\
\text { Facial }\end{array}$ & $\mathbf{K}$ & $\begin{array}{c}\text { Tonalidade } \\
\text { devoz }\end{array}$ & $\mathbf{K}$ \\
\hline Atenção Ativa & .77 & Positiva & .85 & Positiva & .79 \\
Atenção Emocional & .75 & Negativa & .68 & Negativa & .71 \\
Atenção não & .81 & Neutra & .64 & Neutra & .74 \\
continente & & & & & \\
Atenção-continente & .53 & & & & \\
\hline
\end{tabular}

Segundo a Tabela 2, os escores do coeficiente $\mathrm{K}$ para as categorias comportamentais referentes à mãe variaram entre 0.85 e 0.53 . A atenção-continente da mãe foi excluída da análise seguinte, porque o coeficiente $\mathrm{K}$ era abaixo de 0.60 . Todas as outras categorias comportamentais permaneceram na análise.

Tabela 3 - Escores do coeficiente K para as categorias comportamentais referentes ao bebê

\begin{tabular}{|l|c|l|l|l|l|}
\hline Atenção & $\mathbf{K}$ & $\begin{array}{c}\text { Expressão } \\
\text { Facial }\end{array}$ & $\mathbf{K}$ & Olhar & $\mathbf{K}$ \\
\hline Atenção Ativa & .65 & Positiva & .72 & Brilhoso & .61 \\
Atenção Emocional & .61 & Negativa & .67 & Maçante & .68 \\
Atenção relaxada & .27 & & & & \\
& & Apreensão & .68 & Neutro & .56 \\
& & Neutra & .51 & & \\
\hline
\end{tabular}

Em relação aos escores do coeficiente K para as categorias comportamentais referentes ao bebê, estas variaram entre 0.72 e 0.27 . A expressão facial neutra, a atenção relaxada e o olhar neutro do bebê foram excluídos da análise seguinte, porque o coeficiente $\mathrm{K}$ era abaixo de 0.60 . Todas as outras categorias comportamentais permaneceram.

\section{Resultados}

\section{Padrão expressivo e temporal da capacidade de empatia em bebês de 8 e 18 semanas}

A capacidade de empatia em bebês de 8 e 18 semanas foi frequentemente acompanhada pela presença de três índices comportamentais do bebê: expressão facial de apreensão, atenção emocional e olhar brilhoso. A capacidade de empatia assim definida foi, então, investigada em relação à comunicação de emoções negativas e positivas da mãe.

Então, a cada manifestação de um dos três índices comportamentais do bebê, a mudança emocional da mãe mais próxima no tempo era anotada. Em todos os casos, a mudança no estado emocional da mãe ocorreu dentro de um segundo da manifestação de um, ou mais, dos três índices comportamentais associados com a capacidade de empatia infantil.

Considerando a mudança no estado emocional da mãe como ponto de referência, um intervalo de tempo igual de $1 / 2$ segundo antes e 1 segundo depois desta mudança foi definido como um contexto apropriado para analisar o comportamento do bebê. Depois, foi investigado se os três índices comportamentais associados à capacidade de empatia infantil iniciavam dentro deste intervalo, para especificar se eles co-ocorrem, precedem ou seguem um ao outro, e todos eles, a mudança no estado emocional da mãe.

Desta maneira, 440 instâncias de empatia infantil como resposta na comunicação de emoções negativas, e 166 instâncias de empatia infantil como resposta na comunicação de emoções positivas pela mãe, foram examinadas.

Empatia com emoções negativas: Foi achado que das 440 instâncias de comunicação de emoções negativas pela mãe, $66.8 \%$ foi caracterizado pela iniciação de todos os três índices comportamentais do bebê dentro do intervalo de tempo especificado, quando 33.2\% foi caracterizado pela iniciação de um ou dois dos índices comportamentais do bebê dentro do intervalo de tempo especificado. Das instâncias que os três índices comportamentais foram iniciados dentro do intervalo de tempo especificado (294 instâncias), 16\% foram caracterizadas pela iniciação de um ou mais dos índices comportamentais exatamente antes, $18 \%$ pela iniciação simultânea, e 66\% pela iniciação depois da expressão da emoção negativa pela mãe.

Empatia com emoções positivas: Foi achado que das 166 instâncias de comunicação de emoções positivas pela mãe, $24.7 \%$ foram caracterizadas pela iniciação conjunta dos três índices comportamentais do bebê dentro do intervalo de tempo especificado, quando $73.5 \%$ foram caracterizadas pela iniciação de um ou dois dos índices comportamentais do bebê dentro do intervalo de tempo especificado. Das instâncias que os três índices comportamentais foram iniciados dentro do intervalo de tempo especificado (41 instâncias), 7.3\% foram caracterizadas pela iniciação de um ou mais dos índices comportamentais 
do bebê exatamente antes, $22 \%$ pela iniciação simultânea, e 70.7\% pela iniciação depois da expressão da emoção positiva pela mãe. A tabela 4 apresenta a relação entre a qualidade da mudança no estado emocional da mãe e o padrão expressivo da capacidade de empatia do bebê.

Tabela 4 - Qualidade da emoção materna e padrão expressivo da empatia infantil

\begin{tabular}{|l|l|l|}
\hline & $\begin{array}{l}\text { Todos os três } \\
\text { comportamentos do bebê } \\
\text { iniciaram no intervalo de } \\
\text { tempo especificado } \\
\mathrm{N}(\%)\end{array}$ & $\begin{array}{l}\text { Menos do que três } \\
\text { comportamentos do bebê } \\
\text { iniciaram no intervalo de } \\
\text { tempo especificado }\end{array}$ \\
$\mathrm{N}(\%)$
\end{tabular}

Os três comportamentos infantis considerados como definidores da expressão da capacidade de empatia dos bebês foram significativamente mais prováveis de se iniciarem em conjunto no intervalo de tempo especificado de $1 \frac{1}{2}$ segundos quando a mãe comunicava emoções negativas, do que quando ela comunicava emoções não-negativas $\left(\div^{2}(1)=86.493, \mathrm{p}<.001\right)$.

A tabela 5 apresenta a relação temporal entre a expressão de emoção negativa e não-negativa da mãe, e a expressão da capacidade de empatia infantil.

Tabela 5 - Relação temporal entre a expressão de emoção materna e a empatia infantil

\begin{tabular}{|l|c|c|l|}
\hline & Antes & Simultaneamente & Depois \\
\hline $\begin{array}{l}\text { Emoção materna } \\
\text { negativa }\end{array}$ & $16 \%$ & $18 \%$ & $66 \%$ \\
\hline $\begin{array}{l}\text { Emoção materna } \\
\text { não-negativa }\end{array}$ & $7.3 \%$ & $22 \%$ & $70.7 \%$ \\
\hline
\end{tabular}

Segundo a tabela 5, o padrão temporal da expressão da capacidade de empatia não estava associado com a qualidade (positiva - negativa) da mudança emocional na mãe $(\div 2(2)=2.198, \mathrm{p}>.05)$.

\section{Discussão}

Discordando com as teorias tradicionais da Psicologia do Desenvolvimento, como as de Freud e de Piaget que consideraram os recém-nascidos e os bebês pequenos como seres que se relacionam com outras pessoas motivados por impulsos e necessidades fisiológicas, as quais precisam ser satisfeitas, sem intencionalidade ou consciência ativa, o presente estudo verificou que bebês de 8 e 18 semanas apresentam a capacidade de empatia quando em interação face-a-face com suas mães.

Mais especificamente, a capacidade de empatia nos primeiros meses de vida pode ser observada em termos comportamentais e codificada com altos índices de confiabilidade entre observadores. Os comportamentos infantis que, na presente amostra, mostraram-se mais associados com a expressão da capacidade de empatia nos primeiros quatro meses de vida são: a expressão facial de apreensão, o olhar brilhoso e a atenção emocional. Os três comportamentos infantis foram significativamente mais prováveis de iniciarem em conjunto no intervalo de tempo especificado de $1 \frac{1}{2}$ segundos quando a mãe comunicava emoções negativas, do que quando a mãe comunicava emoções não-negativas. Este resultado está de acordo com proposições teóricas anteriores, as quais têm sugerido que a observação da expressão de emoções negativas por alguém seria mais provável motivar comportamentos de empatia, simpatia e altruísmo nos outros, do que a observação da expressão de emoções positivas (Hoffman, 2000). Ainda, o achado que mais do que um comportamento participa na expressão da capacidade de empatia poderia sugerir que a empatia não seja tanto um evento instantâneo, quanto um processo dinâmico, cujo curso está diretamente relacionado com a experiência do parceiro em comunicação.

Os altos índices de confiabilidade de observadores em relação à identificação de comportamentos infantis que encarregam a ação de empatizar dão suporte a confiança que a Fenomenologia atribuiu aos significados. Ressalta-se que os comportamentos definidos como componentes do padrão expressivo da capacidade de empatia não são vistos independentemente da experiência emocional dos bebês; ou seja, o conjunto de ações dos bebês deste estudo não é considerado desprovido de intencionalidade e emoção; ao contrário, sua complexa organização e coerência indicam a capacidade precoce da espécie humana de se envolver em interações mútuas e significativas com parceiros sensíveis aos seus sinais co- 
municativos. Entretanto, a identificação de certos comportamentos como componentes do padrão expressivo da capacidade precoce de empatia não pretende dizer que o padrão da capacidade de empatia acha-se exaustivamente descrito. Ele pode ser mais rico e sofisticado do que o descrito até hoje.

Em relação ao padrão temporal da capacidade de empatia, foi achado que era mais provável o bebê iniciar comportamentos que indicariam empatia com a emoção expressa pela mãe (negativa ou não-negativa) imediatamente depois da manifestação dela, do que antes ou simultaneamente com a expressão da emoção materna. Ainda, o tempo da manifestação (antes, simultaneamente, depois) dos três comportamentos associados com a expressão da empatia infantil não se mostrou associado com a qualidade (emoção negativa ou não-negativa) da mudança no estado emocional da mãe.

Os dados deste estudo encontram na teoria da Intersubjetividade Inata (Trevarthen, 1979, 1998) um contexto teórico mais relevante, do que em teorias que não reconhecem a capacidade de bebês participarem de relacionamentos recíprocos com outras pessoas. Entretanto, há ainda uma outra hipótese a ser testada: a capacidade de empatia encontrada em bebês tão novos seria um dos processos responsáveis pela formação e manutenção de comunicações intersubjetivas entre o bebê e seus cuidadores.

Os resultados deste trabalho, e de outros estudos semelhantes, devem motivar uma revisão das teorias tradicionais da Psicologia do Desenvolvimento, e também sensibilizar os profissionais de áreas afins em relação às implicações teóricas e práticas de dados empíricos que sugerem que recém-nascidos e bebês apresentam um repertório rico de capacidades comunicativas precoces. Assim, a questão da intervenção e prevenção de transtornos mentais que podem ser apresentados ainda no primeiro ano de vida se torna, mais do que nunca, atual e coerente aos novos conhecimentos da área da Psicologia do Desenvolvimento: o conhecimento sobre as capacidades comunicativas precoces de bebês ainda no seu primeiro ano de vida poderia ser aproveitado nos programas de intervenção e prevenção voltados para esta faixa etária. Mais, especificamente, modelos de intervenção e prevenção que reconhecem o bebê como um agente intencional com vontades e emoções próprias e que the atribuem um papel mais ativo no processo terapêutico, precisam ser elaborados, para substituir modelos mais tradicionais que os consideram como seres inacessíveis, mergulhando em fantasias e governados por impulsos e reflexos. Desta maneira, a atuação clínica com esta faixa etária poderá ser mais apropriada, tornando o desenvolvimento de muitas crianças mais saudável.

Micro-Análise da Capacidade de Empatia em Bebês de 8 e 18 Semanas

\section{Categorias Comportamentais Referentes ao Bebê}

\begin{tabular}{|c|c|}
\hline $\begin{array}{l}\text { Atenção } \\
\text { infantil }\end{array}$ & Descrição \\
\hline Ativa & $\begin{array}{l}\text { *Atenção acompanhada por excitação } \\
\text { * Geralmente, durante brincadeiras e comunica- } \\
\text { ção positiva com ambos os parceiros envolvi- } \\
\text { dos. Também, em casos de expressão de raiva ou } \\
\text { protesto ativo. } \\
\text { * Geralmente acompanhada por movimentos ex- } \\
\text { citados, rápidos e abruptos } \\
\text { * O bebê não está relaxado; nem preocupado ou } \\
\text { apreensivo }\end{array}$ \\
\hline Emocional & $\begin{array}{l}\text { * Olhando intensamente a mãe nos olhos } \\
\text { * Interesse intenso junto com preocupação; sem } \\
\text { excitação como na atenção ativa; atenção } \\
\text { questionadora } \\
\text { * As partes superiores do rosto tendem a ser mais } \\
\text { ativas (testa, olhos) do que as partes inferiores do } \\
\text { rosto (boca, lábios, queixo); movimentos lentos } \\
\text { ou imobilidade } \\
\text { * Impressão: algo tem acabado de ser percebido }\end{array}$ \\
\hline Relaxada & $\begin{array}{l}\text { * Olhando relaxadamente, sem excitação; demons- } \\
\text { tração tranqüila de interesse. } \\
\text { * Os componentes do rosto são relaxados. } \\
\text { * Postura relaxada (algumas vezes, movimentos } \\
\text { suaves das extremidades) } \\
\text { * O bebê está quieto e relaxado; não excitado ou } \\
\text { irritado; } \\
\text { Impressão: O bebê esta “ouvindo” a mãe }\end{array}$ \\
\hline
\end{tabular}

\begin{tabular}{|l|l|}
\hline $\begin{array}{l}\text { Olhar do } \\
\text { bebê }\end{array}$ & \multicolumn{1}{c|}{ Descrição } \\
\hline Brilhoso & $\begin{array}{l}\text { * Olhos mais brilhosos do que o usual; olhos bri- } \\
\text { lhantes, cintilantes;exposição mais ampla do glo- } \\
\text { bo ocular } \\
\text { * Impressão: a porcão branca do globo ocular esta } \\
\text { mais luminosa que o natural }\end{array}$ \\
\hline Entristecido & $\begin{array}{l}\text { * Olhos “desligados”, psicologicamente voltados } \\
\text { para dentro }\end{array}$ \\
$\begin{array}{l}* \text { Pálpebras se tornam mais pesadas } \\
* \text { O globo ocular/íris perde sua vivacidade, não pa- } \\
\text { recem luminosos } \\
* \text { Estado emocional não positivo; absorção em si } \\
\text { próprio provável }\end{array}$ \\
\hline Neutro & * Todos os outros tipos/qualidades de olhar \\
\hline
\end{tabular}




\begin{tabular}{|l|l|}
\hline $\begin{array}{c}\text { Estado } \\
\text { emocional/ } \\
\text { Beb ê }\end{array}$ & \multicolumn{1}{|c|}{ Descrição } \\
\hline Positivo & $\begin{array}{l}\text { * Alegria/ interesse; sem rugas, lábios afinados ou } \\
\text { olhos entristecidos }\end{array}$ \\
\hline Negativo & $*$ Tristeza, raiva, agitação/ansiedade \\
\hline $\begin{array}{l}\text { Preocupado/ } \\
\text { Apreensivo }\end{array}$ & $\begin{array}{l}\text { * Inquietação, preocupação, questionamento, } \\
\text { olhos alertas. } \\
\text { * Partes superiores do rosto levemente contraí- } \\
\text { das; partes inferiores do rosto geralmente relaxa- } \\
\text { das }\end{array}$ \\
\hline Neutro & $\begin{array}{l}* \text { Expressão facial sem conotações emocionais } \\
\text { específicas }\end{array}$ \\
\hline
\end{tabular}

Categorias Comportamentais Referentes a Mãe

\begin{tabular}{|c|c|}
\hline $\begin{array}{l}\text { Atenção } \\
\text { materna }\end{array}$ & Descrição \\
\hline Ativa & $\begin{array}{l}\text { * Excitação, olhos brincalhões, geralmente du- } \\
\text { rante momentos de brincadeira e comunicação } \\
\text { ativa, positiva com ambos os parceiros envolvi- } \\
\text { dos } \\
\text { * Frequentemente, durante canções infantis e } \\
\text { brincadeiras } \\
\text { * Algumas vezes acompanhada por expressões } \\
\text { faciais exageradamente positivas }\end{array}$ \\
\hline Emocional & $\begin{array}{l}\text { * Olhar profundo, o olhar se torna emocional- } \\
\text { mente mais pesado, (isto é o observador tem a } \\
\text { sensação que a mãe comunica emoções a criança } \\
\text { através da maneira que ela interage com ela) } \\
\text { * Geralmente, movimentos lentos ou imobilida- } \\
\text { de } \\
\text { * Os olhos ou se tornam mais brilhantes ou } \\
\text { entristecidos, eles não suportam neutralidade } \\
\text { ou um estado emocional relaxado/neutro } \\
\text { * A diferença entre atenção emocional e atenção } \\
\text { relaxada é a diferença na valência emocional sus- } \\
\text { tentada. A valência emocional sustentada pela } \\
\text { atenção emocional é maior e mais intensa }\end{array}$ \\
\hline $\begin{array}{l}\text { Relaxada/ } \\
\text { Continente }\end{array}$ & $\begin{array}{l}\text { * A mãe esta relaxada; neutra para positiva ou } \\
\text { positiva sem excitação; Ela oferece um senti- } \\
\text { mento de que está apta a sustentar e conter a } \\
\text { criança com seu olhar } \\
\text { * Seu olhar, embora relaxado, comunica afeição } \\
\text { e sensação de segurança para o bebê }\end{array}$ \\
\hline $\begin{array}{l}\text { Relaxada/ } \\
\text { Não- } \\
\text { continente }\end{array}$ & $\begin{array}{l}\text { * A mãe esta relaxada, mas não comunica afeição } \\
\text { e segurança para o bebê; não “contem” o bebê; } \\
\text { desapontamento implícito, rejeição e criticas } \\
\text { podem ser observadas } \\
\text { * Sua atenção poderia comunicar indiferença }\end{array}$ \\
\hline
\end{tabular}

\begin{tabular}{|c|l|}
\hline $\begin{array}{c}\text { Tonalidade } \\
\text { de voz }\end{array}$ & \multicolumn{1}{|c|}{ Descrição } \\
\hline Positiva & $\begin{array}{l}\text { * Alegria; intenção brincalhona, sem sinal de } \\
\text { negatividade }\end{array}$ \\
\hline Negativa & $\begin{array}{l}\text { * Triste; critica, desapontada; tonalidade de voz } \\
\text { fria, seca, sem afeição positiva }\end{array}$ \\
\hline Neutra/Outra & $\begin{array}{l}\text { * Tonalidade de voz sem conotações emocio- } \\
\text { nais específicas }\end{array}$ \\
\hline
\end{tabular}

\begin{tabular}{|l|l|}
\hline $\begin{array}{l}\text { Estado emocio- } \\
\text { nal/Mãe }\end{array}$ & \multicolumn{1}{c|}{ Descrição } \\
\hline Positivo & $\begin{array}{l}\text { * Alegria, interesse, possivelmente afeição, } \\
\text { carinho } \\
\text { * “Ar brincalhão” }\end{array}$ \\
\hline Negativo & $\begin{array}{l}\text { * Tristeza, humor baixo, expressão facial pe- } \\
\text { sada, olhos não “vivos”, boca geralmente fe- } \\
\text { chada, lábios afinados, pressionados entre si ou } \\
\text { com curvatura para baixo } \\
\text { * Rejeição/Desapontamento: expressão facial } \\
\text { endurecida, fria, sem afeição ou carinho, lábios } \\
\text { fechados, pressionados, algumas vezes sobran- } \\
\text { celhas elevadas em criticismo. }\end{array}$ \\
\hline Neutro/Outro & $\begin{array}{l}\text { * Expressão facial sem conotações emocio- } \\
\text { nais específicas }\end{array}$ \\
\hline
\end{tabular}

\section{Referências}

Brazelton, T. B., Koslowski, B. \& Main, M. (1974). The Origins of Reciprocity: The early motherinfant interaction. In M. Lewis, \& L. A. Rosenblum (Eds.), The Effect of the Infant on Its Caregiver. London: Krieger Publishing Company.

Cooper, P. J., Murray, L., Hooper, R. \& West, A. (1996). The Development and Validation of a Predictive Index for Postpartum Depression. Psychological Medicine, 26, 627-634.

Hatzinikolaou, K. (2002). The Development of Empathy and Sympathy in the First Year. PhD thesis, The University of Reading, Reading, England.

Hatzinikolaou, K. \& Murray, L. (2001). Postnatal depression, different maternal interactive styles and empathy in 2, 41/2 and 12-month-old infants. Xth European Conference on Developmental Psychology: Abstracts, (p.14), Uppsala, Sweden.

Hoffman, L. M. (2000). Empathy and Moral Development: Implications for caring and justice. Cambridge: Cambridge University Press.

Kugiumutzakis, G. (1998). Neonatal imitation in the intersubjective companion space. In S. Bråten, (Ed.), Intersubjective communication and emotion in early ontogeny, (pp. 63-88). Cambridge: Cambridge University Press.

Murray, L. (1989). Winnicott and the Developmental Psychology of Infancy. British Journal of Psychotherapy, 5(3), 333-348. 
Murray, L. \& Trevarthen, C. (1985). Emotional Regulation of Interactions Between Two-Month-Olds and Their Mothers. In T. M. Field \& N. A. Fox (Eds.), Social Perception in Infants. (pp. 101-125). Norwood, N.J.: Ablex.

Reddy, V. (2003). On being the object of attention: implications for self-other consciousness. Trends in Cognitive Sciences, 7(9), 397-402

Stern, D. N. (2000). The interpersonal world of the infant: A view from psychoanalysis and development psychology. New York: Basic Books.

Trevarthen, C. (1979). Communication and Cooperation in Early Infancy: A description of primary intersubjectivity. In M. Bullowa (Ed.), Before Speech: The beginning of interpersonal communication (pp. 321-348). Cambridge: Cambridge University Press.

Trevarthen, C. (1998). The concept and foundations of infant intersubjectivity. In S. Bråten (Ed.), Intersubjective communication and emotion in early ontogeny, (pp. 15-46). Cambridge: Cambridge University Press.

Trevarthen, C., \& Aitken, J. A. (2001). Infant Intersubjectivity: Research, theory and clinical applications. Journal of Child Psychology and Psychiatry, 42(1), 3-48.

O presente trabalho foi derivado da tese de doutorado da autora supracitada em University of Reading, England. O estudo foi concluído com o apoio financeiro de Winnicott Research Unit, Department of Psychology, University of Reading e Alexander Onassis Foundation, Greece. 